\title{
Thrombocytopenia in a Patient with Severe Combined Immune Deficiency: An Unusual Cause
}

\author{
Farrukh Sheikh ${ }^{1 *}$, Safiah Sumayli ${ }^{1}$, Hasan Hakami ${ }^{2}$, Agha M Rehan Khaliq ${ }^{1,3}$, Sulaiman \\ Al Gazlan ${ }^{1}$, Hasan Alrayes ${ }^{1}$, Ghuzayel Al-Dawsari ${ }^{4}$, Riad El Fakih ${ }^{4}$ and Rand Arnaout ${ }^{1,3,5}$
}

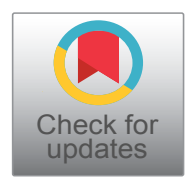

${ }^{1}$ Department of Medicine, Section of Allergy and Immunology, King Faisal Specialist Hospital \& Research Centre, Riyadh, Kingdom of Saudi Arabia

${ }^{2}$ Department of Medicine, King Faisal Specialist Hospital and Research Center, Riyadh, Kingdom of Saudi Arabia

${ }^{3}$ Alfaisal University, Riyadh, Kingdom of Saudi Arabia

${ }^{4}$ Oncology Center, Section of Adult Hematology/HSCT, King Faisal Specialist Hospital and Research Center, Riyadh, Saudi Arabia ${ }^{5}$ Department of Pediatric, Section of Allergy and Immunology, King Faisal Specialist Hospital and Research Center, Riyadh, Kingdom of Saudi Arabia

*Corresponding author: Farrukh Sheikh, Department of Medicine, Section of Allergy \& Immunology, King Faisal Specialist Hospital \& Research Centre, Riyadh, Kingdom of Saudi Arabia, Tel: +96614427492, Fax: +96614427499

\begin{abstract}
We report the first case of severe intractable thrombocytopenia in a patient with adenosine deaminase deficiency, Severe Combined Immune Deficiency (SCID), necessitating hematopoietic stem cell transplant. This patient developed severe thrombocytopenia from polyethylene glycol adenosine deaminase and needed a hematopoietic stem cell transplant as an adolescent. She did well afterwards, overall. Although rare, thrombocytopenia can result from polyethylene glycol adenosine deaminase. Hematopoietic stem cell transplant may be an option in SCID patients with intractable thrombocytopenia, even at a later age.
\end{abstract}

\section{Introduction}

Adenosine deaminase (ADA) deficiency is a primary immune deficiency disease which consists of almost one third of all cases of autosomal recessive SCID [1]. It presents during the early months of life and is characterized by a deficient number of and function of lymphocytes (i.e., T-B-NK-SCID). ADA-SCID is managed in several ways including enzyme replacement therapy with polyethylene glycol-modified adenosine deaminase (PEG-ADA) [2]. which is generally well tolerated, however several side effects have been reported with its use [3]. Thrombocytopenia due to PEG-ADA is a rare complication with an unclear mechanism. Therapy with intravenous immunoglobulin (IVIG) has been reported to improve PEG-ADA associated thrombocytopenia in at least one of the case reports [4]. The definitive and curative treatment for ADA-SCID is hematopoietic stem cell transplant (HCT) from an HLA identical sibling donor [2,5-7]. Other modalities include HCT from matched family donors (MFD) or from a matched unrelated donor (MUD). MUD has much less rewarding results secondary to higher transplant related mortality. Recent modality for treatment is gene therapy, although it is still not used widely in clinical practice [8].

\section{Case Report}

We describe a case of ADA-SCID received HCT as an adolescent from a MUD after termination of her PEG ADA treatment due to severe thrombocytopenia induced by PEG-ADA. Our patient is a 19-year-old female from consanguineous parents who presented at the age of 3 years with severe chickenpox, meningitis and history of recurring lung infections. Genetic workup confirmed the mutation for ADA-SCID (not shown). Her ADL level was also low and the patient was started on PEGADA. She was kept in PEG-ADA from almost 13 years. The patient was compliant with PEG-ADA treatment.

Citation: Sheikh F, Sumayli S, Hakami H, Khaliq AMR, Al Gazlan S, et al. (2018) Thrombocytopenia in a Patient with Severe Combined Immune Deficiency: An Unusual Cause. Int J Aller Medications 4:035. doi.org/10.23937/2572-3308.1510035

Accepted: September 20, 2018: Published: September 22, 2018

Copyright: (C) 2018 Sheikh F, et al. This is an open-access article distributed under the terms of the Creative Commons Attribution License, which permits unrestricted use, distribution, and reproduction in any medium, provided the original author and source are credited. 


\section{Platelet Count Over Time}

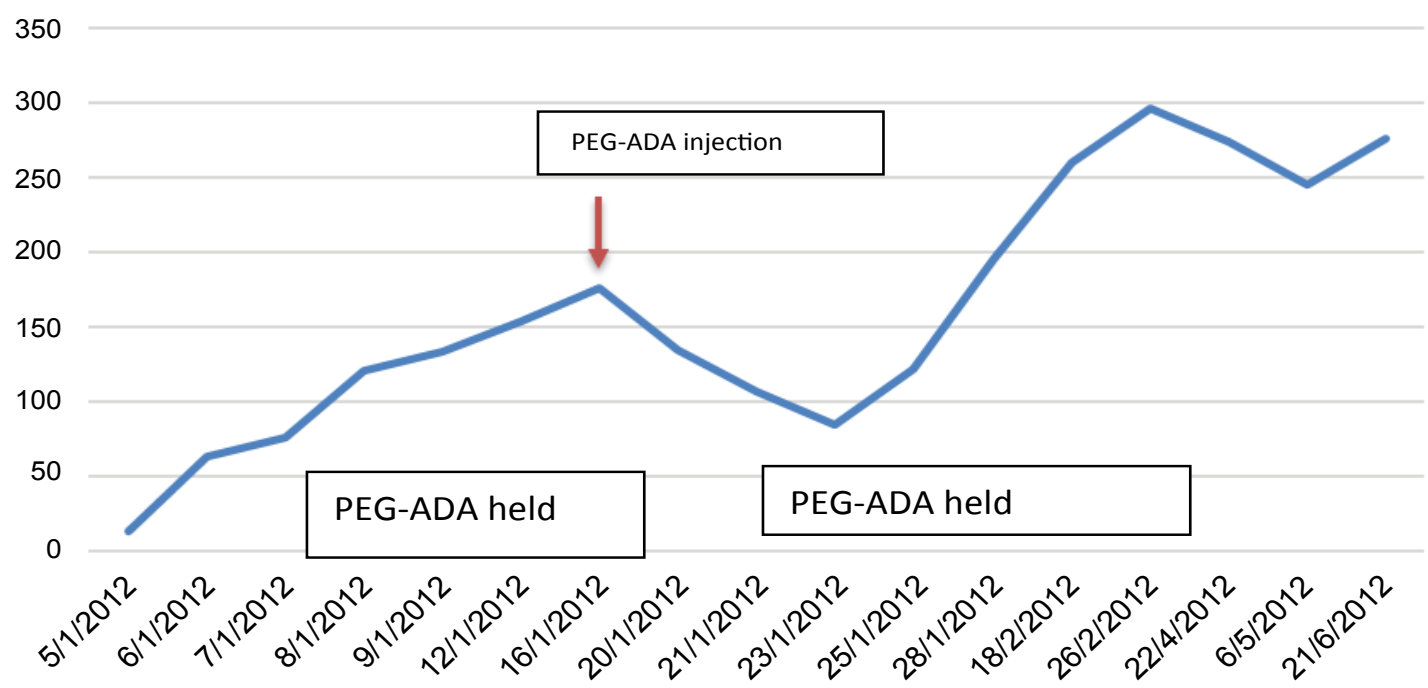

Figure 1: The trend of platelet counts through PEG-ADA treatment.

At the age of 15 years, she presented with pulmonary and intraperitoneal hemorrhages and was found to have severe thrombocytopenia. Initial platelet count was $5000 / \mathrm{mcL}$ and hemoglobin was $5 \mathrm{~g} / \mathrm{dl}$. She was treated supportively in addition to IVIG and pulse steroids for idiopathic thrombocytopenia (ITP) and hemolytic anemia as workup revealed no cause for thrombocytopenia. There was no history of alcohol use. The patient was negative for Hepatitis $\mathrm{C}$ detection or quantitation. HIV was also negative.

PEG-ADA was held initially because of profound thrombocytopenia. The patient stabilized and her platelet count improved and it was deemed safe to resume her intramuscular PEG-ADA injection. Soon afterwards, the patient's platelet count as well as hemoglobin level began to drop again. PEG-ADA was held at that time as a possible trigger for thrombocytopenia.

Both attacks of thrombocytopenia were noticed to be during the administration of PEG-ADA, and both subsided by holding PEG-ADA (Figure 1). Based on this observation, the patient received a diagnosis of PEG-ADA induced thrombocytopenia, as the only new medication given was PEG-ADA at that time. The patient had a score of 8 on Naranjo algorithm making it highly probable that PEG-ADA was the cause of this patient's thrombocytopenia (Supplementary File 1) $[9,10]$. Thrombocytopenia was also the term for the adverse event from the Medical Dictionary for Regulatory Activities. (medDRA) [11]. Thrombocytopenia has been reported in patients receiving PEG-ADA [4]. however, the unusual thing about our case is that it occurred after the patient was on it for so long, and it was resistant to all treatments, except stopping PEG-ADA itself.

Given her refractory thrombocytopenia, we had to shift from PEG-ADA to another modality of treatment. The patient was put on IVIG and sulfamethoxazole-tri- methoprim, awaiting a suitable donor. There was no available family donor, so she underwent HCT from MUD using Busulphan/Fludarabine/antithymocyte globulin (conditioning regimen) and Mycophenolate \& Cyclosporine for graft versus host disease (GVHD) prophylaxis. The source of stem cells was peripheral blood at a dose of $5 \times 106 / \mathrm{Kg}$ of the recipient. After transplant, she showed good engraftment and incremental clinical improvement.

\section{Discussion}

PEG-ADA is generally well tolerated by patients with ADA-SCID [3]. In previously published reports of PEG-ADA causing thrombocytopenia, immune dysregulation was attributed as a possible cause when starting PEG-ADA in a patient for the first time. It is unclear however, why our patient developed thrombocytopenia after being on PEG-ADA for so many years. For all published studies regarding $\mathrm{HCT}$ in ADA-SCID, none of them reported transplantation results, complications, or long-term survival in adolescent patients. In our reported case, after intolerance of PEG-ADA which was complicated by persistent severe thrombocytopenia, we decided to transplant our patient from an MUD because no matched relative was available. She had good immune system recovery following HCT.

In summary, PEG-ADA can induce thrombocytopenia, possibly through immune dysregulation or other mechanisms and good recovery can be achieved after discontinuation of PEG-ADA.

$\mathrm{HCT}$ in this case was the mandated modality of treatment for this adolescent to avoid the unexpected severe complication of PEG-ADA and to prevent the patient from drifting to SCID status again.

\section{Conflict of Interests}

The authors report no conflict of interests. 


\section{References}

1. Buckley RH, Schiff RI, Schiff SE, Markert ML, Williams LW, et al. (1997) Human severe combined immunodeficiency: Genetic, phenotypic, and functional diversity in one hundred eight infants. J Pediatr 130: 378-387.

2. Gaspar HB (2010) Bone marrow transplantation and alternatives for adenosine deaminase deficiency. Immunol Allergy Clin North Am 30: 221-236.

3. Booth C, Gaspar HB (2009) Pegademase bovine (PEGADA) for the treatment of infants and children with severe combined immunodeficiency (SCID). Biologic 3: 349-358.

4. Hershfield MS, Chaffee S, Sorensen R (1993) Enzyme replacement therapy with polyethylene glycol-adenosine deaminase in adenosine deaminase deficiency: Overview and case reports of three patients, including two now receiving gene therapy. Pediatr Res 33: S42-S47.

5. Markert ML, Hershfield MS, Schiff RI, Buckley RH (1987) Adenosine deaminase and purine nucleoside phosphorylase deficiencies: Evaluation of therapeutic interventions in eight patients. J Clin Immunol 7: 389-399.
6. Hassan A, Booth C, Brightwell A, Allwood Z, Veys P, et al. (2012) Outcome of hematopoietic stem cell transplantation for adenosine deaminase-deficient severe combined immunodeficiency. Blood 120: 3615-3624.

7. Rubinstein A, Hirschhorn R, Sicklick M, Murphy RA (1979) In vivo and in vitro effects of thymosin and adenosine deaminase on adenosine-deaminase-deficient lymphocytes. N Engl J Med 300: 387-392.

8. Ferrua F, Brigida I, Aiuti A (2010) Update on gene therapy for adenosine deaminase-deficient severe combined immunodeficiency. Curr Opin Allergy Clin Immunol 10: 551-556.

9. Naranjo CA, Busto U, Sellers EM, Sandor P, Ruiz I, et al. (1981) A method for estimating the probability of adverse drug reactions. Clin Pharmacol Ther 30: 239-245.

10. Busto U, Naranjo CA, Sellers EM (1982) Comparison of two recently published algorithms for assessing the probability of adverse drug reactions. Br J Clin Pharmacol 13: 223227.

11. Brown EG, Wood L, Wood S (1999) The medical dictionary for regulatory activities (MedDRA). Drug Saf 20: 109-117.

Supplementary File 1: Naranjo ADR probability scale [9].

\begin{tabular}{|c|c|c|c|c|c|}
\hline S.No & Question & Yes & No & Don't know & Score \\
\hline 1 & Are there previous conclusive reports on this reaction? & +1 & 0 & 0 & 1 \\
\hline 2 & Did the adverse event appear after the suspected drug was administered? & +2 & -1 & 0 & 2 \\
\hline 3 & $\begin{array}{l}\text { Did the adverse reaction improve when the drug was discontinued, or a specific } \\
\text { antagonist was administered? }\end{array}$ & +1 & 0 & 0 & 1 \\
\hline 4 & Did the adverse reaction reappear when the drug was readministered? & +2 & -1 & 0 & 2 \\
\hline 5 & $\begin{array}{l}\text { Are there alternative causes (other than the drug) that could on their own have } \\
\text { caused the reaction? }\end{array}$ & -1 & +2 & 0 & 2 \\
\hline 6 & Did the reaction reappear when a placebo was given? & -1 & +1 & 0 & 0 \\
\hline 7 & $\begin{array}{l}\text { Was the drug detected in the blood (or other fluids) in concentrations known to } \\
\text { be toxic? }\end{array}$ & +1 & 0 & 0 & 0 \\
\hline 8 & $\begin{array}{l}\text { Was the reaction more severe when the dose was increased, or less severe } \\
\text { when the dose was decreased? }\end{array}$ & +1 & 0 & 0 & 0 \\
\hline 9 & $\begin{array}{l}\text { Did the patient have a similar reaction to the same or similar drug in any previous } \\
\text { exposure? }\end{array}$ & +1 & 0 & 0 & 0 \\
\hline \multirow[t]{2}{*}{10} & Was the adverse event confirmed by any objective evidence? & +1 & 0 & 0 & 0 \\
\hline & Total & & & & 8 points \\
\hline
\end{tabular}

